\title{
Change in color and tocopherol content during heating of soybean oil in the presence of different antioxidants
}

\author{
Young-Min Kim, Jung-Ah Shin, Ki-Teak Lee* \\ Department of Food Science and Technology, Chungnam National University, Daejeon 34134, Korea
}

\section{가열 산화중 대두유의 색변화와 토코페롤 잔존에 미치는 항산화제의 영향}

\author{
김영민 · 신정아 · 이기택* \\ 충남대학교 식품공학과
}

\begin{abstract}
In this study, the thermal oxidation of soybean oil (SBO) was investigated in the presence of 200 ppm of antioxidants, namely, caffeic acid phenethyl ester (CAPE), caffeic acid (CA), ascorbyl palmitate (AP), and a-tocopherol (a-TO). ${ }^{1}$ H-NMR analysis shows that the addition of CAPE into SBO resulted in a smaller area of aldehydes peak as compared with the addition of AP, CA, and a-tocopherol. Thus, the addition of CAPE could reduce the thermal oxidation of SBO to some extent. The $L^{*}$ values (brightness) of SBO with CAPE, a-tocopherol, and AP were significantly higher than that in the absence of antioxidants (blank) after $32 \mathrm{~h}$ of thermal oxidation, but $\Delta \mathrm{E}$ of the overall color change was not significantly different among these. During the thermal oxidation, the decrease in the $a$ - and $\gamma$-tocopherol contents was greater than that in the $\delta$-tocopherol content. CA, the most polar antioxidant used in this experiment, showed no significant effect on the loss of $\gamma$-tocopherol as compared with CAPE and AP. However, CAPE synthesized from CA was the most effective in retaining the tocopherol isomers during the initial heating stage than any other antioxidants used herein.
\end{abstract}

Key words : caffeic acid phenethyl ester, caffeic acid, ascorbyl palmitate, thermal oxidation, tocopherol retention

\section{서 론}

유지(fats and oils)는 식품에 맛과 향을 제 공하며 인체에 도 중요한 영향을 끼친다. 그중에서도 식품을 통해 섭취를 해야 하는 linoleic $\operatorname{acid}(\mathrm{C} 18: 2, \omega-6)$ 와 a-linolenic $\operatorname{acid}(\mathrm{C} 18: 3$, $\omega-3)$ 와 같은 필수지방산들은 탄소 체인에 이중결합을 2-3개 가지고 있는 불포화 지방산이다(1). 이와 같은 불포화 지방 산들은 이중결합을 가지고 있지 않은 포화지방산들보다 저장 및 취급 중에 산소, 빛, 열과 같은 요인들에 의해 더욱 쉽게 산화되며, 이는 특히 불포화 지방산을 다량 함유하고 있는 유지 또는 이를 함유한 식품의 산화 안정성에 부정적

*Corresponding author. E-mail : ktlee@cnu.ac.kr Phone : 82-42-821-6729, Fax : 82-42-821-8785

Received 15 March 2019; Revised 31 May 2019; Accepted 10 June 2019.

Copyright (c) The Korean Society of Food Preservation. All rights reserved.
영향을 미친다(1).

유지는 식품조리과정에서 열전달 매체로써 이용되며, 조 리 후 식품에 고유한 풍미와 조직감을 향상시켜준다. 이때 조리 온도는 튀김(frying)의 경우 일반적으로 $150-190^{\circ} \mathrm{C}$ 이 다 $(2,3)$. 유지의 산화는 공기 중의 산소를 흡수하며 일어나 는 자동산화뿐만 아니라 가열에 의하여 분해 및 중합이 일어나며, 이로 인하여 유지에서 공액이중결합의 증가, 색 변질, 변향(flavor reversion), 산화생성물의 증가, 중합반응 으로 인한 점도 증가 등 물리화학적 변화를 초래한다 $(2,4)$. 가열산화는 자동산화에서보다 급격히 가속화되어 일어나 며, 오랜 시간 동안의 가열 과정 중에 발생되는 산화물들은 동맥경화, 간 손상 등 인체에 해로운 영향을 준다고 보고되 고 있다(5). 이와 더불어 산화에 의하여 유지 또는 유지를 함유한 식품의 색과 향의 변화가 일어나게 되는데, 이러한 변화는 산화 과정 중에 발생되는 여러 종류의 aldehydes, ketone과 같은 2차 산화물들이 그 요인이 된다(4). 이에 따라 식품 산업계에서는 산화에 대한 안정성을 유지하기 위하여 
항산화제가 널리 사용되고 있다. 특히, 유지를 가열할 때 유지가 자연적으로 함유하고 있는 천연항산화제 혹은 이들 의 인위적 첨가는 산화를 억제시키기 때문에 유지 및 유지 함유 식품의 품질을 안정적으로 유지할 수 있다. 일반적으 로 많이 사용되는 천연 항산화제인 토코페롤(tocopherol)과 ascorbyl palmitate는 대표적인 지용성 항산화제로서 산화단 계에서 생성되는 라디칼에 수소를 공여하여 라디칼의 생성 을 막거나 저해하는 역할을 할 수 있다(6). 한편 caffeic acid phenehtyl ester(CAPE)는 caffeic acid와 phenethyl alcohol의 에스테르 화합물로서 항산화능이 보고되었다 $(7,8)$.

본 연구에서는 caffeic acid phenethyl ester(CAPE), caffeic acid(CA), ascorbyl palmitate(AP), 그리고 a-tocopherol(a -TO)을 대두유(SBO)에 첨가한 후, 가열 산화 조건에서 색상 (Hunter parameters, $\mathrm{L}^{*}, \mathrm{a}^{*}, \mathrm{~b}^{*}$, 그리고 $\Delta \mathrm{E}$ )의 변화와 토코페 롤의 함량 변화를 평가하여 각 항산화물질이 유지 가열시 어떠한 영향을 받는지를 관찰하였다.

\section{재료 및 방법}

\section{실험재료 및 시약}

본 연구에서 사용한 대두유(SBO)는 대형마켓(Daejeon, Korea)에서 구입하였고, 실험에 항산화제로 사용된 $a$ -tocopherol(a-TO), ascorbyl palmitate(AP)도 Sigma-Aldrich Co., (St. Louis, MO, USA)에서 구입하여 사용하였다. CAPE 는 선행된 연구에서 기술한 방법을 이용하여 caffeic acid와 phenethyl alcohol의 화학적 반응을 이용한 esterification반 응으로 제조하였으며 $(7,8), \mathrm{CAPE}$ 를 합성하기 위한 caffeic acid, phenethyl alcohol, dicyclohexylcarbodiimide(DCC), tetrahydrofuran(THF), Supelclean ${ }^{\mathrm{TM}}$ LC-Si solid-phase extraction tube $(6 \mathrm{~mL})$ 는 Sigma-Aldrich Co.에서 구입하였다. 추출에 사용된 용매는 normal grade를 사용하였으며 HPLC 분석에 사용한 용매 및 시약들은 HPLC grade 분석용 시약 을 Fisher Scientific(Seoul, Korea)에서 구입하여 사용하였 다. CAPE 합성 및 분리를 확인하기 위해 사용한 TLC silica gel 60 F254은 MERCK Co. (Darmstadt, Germany)에서 구입 하였다.

\section{대두유의 가열 산화}

가열 산화 조건에서의 유지 산화는 다음과 같이 수행되 었다. $\mathrm{SBO}(40 \mathrm{~g})$ 을 $100 \mathrm{~mL}$ screw cap vial에 취한 후 $\mathrm{CA}$, CAPE, a-TO 및 AP을 각각 $200 \mathrm{ppm}(8 \mathrm{mg})$ 씩 첨가하였다. 균질화를 위해 $50^{\circ} \mathrm{C}$ 에서 $20 \mathrm{~min}$ 동안 sonication(Kodo, Daejeon, Korea)한 후, 각 vial을 cap이 없는 상태에서 $180 \pm$ $5^{\circ} \mathrm{C}$ 로 유지시킨 히팅 블록에서 가열 산화 반응을 하였다. 반응은 첫날에 4시간을 가열산화한 후 시료를 채취하였고, 4 시간을 또다시 수행하여 총 8 시간을 가열산화 하였다. 이
후 계속해서 매일 8시간씩 가열산화하여 총 32 시간 $(4,8$, 16,24 및 32 시간)동안 시료를 채취하였다. 반응이 끝난 후 각 시간별로 취한 시료는 $5 \mathrm{~mL}$ 씩 나누어 질소 충진 후 분석하기 전까지 $-20^{\circ} \mathrm{C}$ 에서 보관하였다. 실험에 적용된 시간대별 반응이 끝난 후 새로운 $\mathrm{SBO}$ 의 추가는 하지 않았 고, 가열 반응이 끝난 시료는 vial cap을 닫은 채 다음날 실험 전까지 상온의 후드 안에서 방치하였다.

\section{${ }^{1} \mathrm{H}-\mathrm{NMR}$ 분석}

산화생성물인 aldehydes는 ${ }^{1} \mathrm{H}-\mathrm{NMR}$ (BRUKER AVANCE III 600, Bruker, Germany)로 분석하였다. 가열 산화된 유지 시료(약 $50 \mathrm{mg}$ )는 $700 \mu \mathrm{L}$ 의 chloroform-d[purity $99.8 \%$, contain $0.1 \%$ tetramethylsilane (TMS)]에 녹여서 NMR tube(5-mm diameter)에 옮겼다. ${ }^{1} \mathrm{H}-\mathrm{NMR}$ 분석을 위한 조건 은 $12335.5 \mathrm{~Hz}$ (spectral width), 16 rounds(scan number), $2.656 \mathrm{~s}$ (acquisition time)이었다. Chemical shifts( $(\delta)$ 는 TMS 를 $\delta=0 \mathrm{ppm}$ 으로 설정 후 획득하였다. Aldehyde(n-alkenals, 4,5-epoxy-(E)-2-alkenals, (E,E)-2,4-alkadienals, and (E)-2alkenals)의 signal은 이전의 발표된 연구결과들(8-10)과 비 교하였다.

색측정

색 변화 측정은 색차계(Color Techno System Corp, Tokyo, Japan)를 이용하여 측정하였으며, Hunter체계 Hunter units $L^{*}=\left[100\right.$ (white), 0(black)], $a^{*}=[+a($ red), $-\mathrm{a}$ (green)], $\mathrm{b}^{*}=[+\mathrm{b}$ (yellow), -b(blue)]를 기준으로 하였다. Calibration은 백판(white standard)을 이용하여 수행하였다. Total color difference $(\Delta \mathrm{E})$ 는 초기 $\mathrm{SBO}$ 을 기준으로 구하였으며 식은 아래와 같다.

$\Delta \mathrm{L}=\mathrm{L}_{\text {sample }}-\mathrm{L}_{\text {standard }}(+\Delta \mathrm{L}$ : means sample is lighter than standard/- $\triangle \mathrm{L}$ : means sample is darker than standard)

$\triangle \mathrm{a}=\mathrm{a}_{\text {sample }} \mathrm{a}_{\text {standard }}(+\Delta \mathrm{a}$ : means sample is redder than standard/- $\triangle \mathrm{a}$ : means sample is greener than standard)

$\Delta \mathrm{b}=\mathrm{b}_{\text {sample }}-\mathrm{b}_{\text {standard }}(+\Delta \mathrm{b}$ : means sample is yellower than standard/- $\triangle \mathrm{b}$ : means sample is bluer than standard)

$$
\Delta \mathrm{E}=\sqrt{\Delta L^{2}+\Delta a^{2}+\Delta b^{2}}
$$

\section{Tocopherol 분석}

유지 가열 산화에 따른 토코페롤의 조성 변화 및 감소량 을 확인하기 위해 형광검출기가 연결된 HPLC(G1311A, Agilent Technologies, Germany)를 이용하여 분석하였고, 토 코페롤의 추출은 알칼리 비누화법을 이용하였다(11). 추출 관에 시료 $500 \mathrm{mg}$ 과 $6 \%$ pyrogallol ethanol용액 $10 \mathrm{~mL}$ 를 첨가하고 2 분동안 vortex로 혼합한 후 질소 충진하여 10 분 동안 sonication을 하였다. 그 후 $60 \% \mathrm{KOH}$ 용액 $8 \mathrm{~mL}$ 를 첨가하고 균질화 후 $75^{\circ} \mathrm{C}, 100 \mathrm{rpm}$ shaking water 
bath(BS-21, Lab Companion, Ramsey, MN, USA)에서 1 시 간 동안 검화 반응을 진행하였다. 토코페롤을 추출하기 위 하여 추출용매 hexane:ethyl acetate( $85: 15, \mathrm{v} / \mathrm{v}, 0.01 \%$ BHT) $15 \mathrm{~mL}, 2 \% \mathrm{NaCl}$ 용액 $20 \mathrm{~mL}$ 를 넣고 $2 \mathrm{~min}$ 동안 vortex로 혼합한 후 방치하여 층 분리를 유도한 뒤 상층액만을 취해 anhydrous sodium sulfate column을 통과시켜 수분을 제거하 였다. 이를 총 3회 반복 한 후 $50 \mathrm{~mL}$ volumetric flask에 정용하였다. 토코페롤을 분석하기 위하여 추출물 $5 \mathrm{~mL}$ 를 취한 뒤 질소를 이용하여 용매를 완전히 제거한 후 $2.5 \mathrm{~mL}$ 의 hexane에 녹여 $0.50 \mu \mathrm{m}$ syringe filter(Toyo Roshi Kaisha, Ltd., Japan)로 여과하였고, 이를 $20 \mu \mathrm{L}$ 를 주입하여 HPLC로 분석하였다. 사용된 column은 LiChrospher ${ }^{\circledR}$ Diol 100 (Merck KGaA, 250×4 mm, $5 \mu \mathrm{m}$, Darmstadt, Germany)이었 고, detector는 1200 series 형광검출기[fluorescence(Ex $\lambda$ $=290 \mathrm{~nm}, \mathrm{Em} \lambda=330 \mathrm{~nm}$ ), Agilent Technologies, Palo Alto, CA, USA]을 사용하였다. 이동상은 hexane:2-propanol (99.4:0.6, v/v)로 조제한 후 $1 \mathrm{~mL} / \mathrm{min}$ 의 유속으로 등용리하
여 분석하였다. 토코페롤의 함량은 $a-, \gamma-$, 그리고 $\delta$ -tocopherol 표준물질 분석을 이용하여 정량하였다.

\section{통계처리}

두 번의 측정 결과는 평균값과 편차로 표기하였고 결과 값에 유의적 차이를 검증하기 위해 SAS statistical Computer Package V.9.2(SAS institute., cary, NC) 프로그램의 Duncan's multiple range test를 실시하여 $95 \%(\mathrm{p}<0.05)$ 수준 에서 검증하였다(12).

\section{결과 및 고찰}

\section{${ }^{1} \mathrm{H}-\mathrm{NMR}$ 을 이용한 aldehydes류 모니터링}

Fig. 1 에서 ${ }^{1} \mathrm{H}-\mathrm{NMR}$ 을 이용하여 유지의 2 차 산화물인 aldehydes류의 변화량을 나타내었다. 연구 결과에 따르면 유지의 산화 과정 중에 발생되는 산화물들은 ${ }^{1} \mathrm{H}-\mathrm{NMR}$ 로

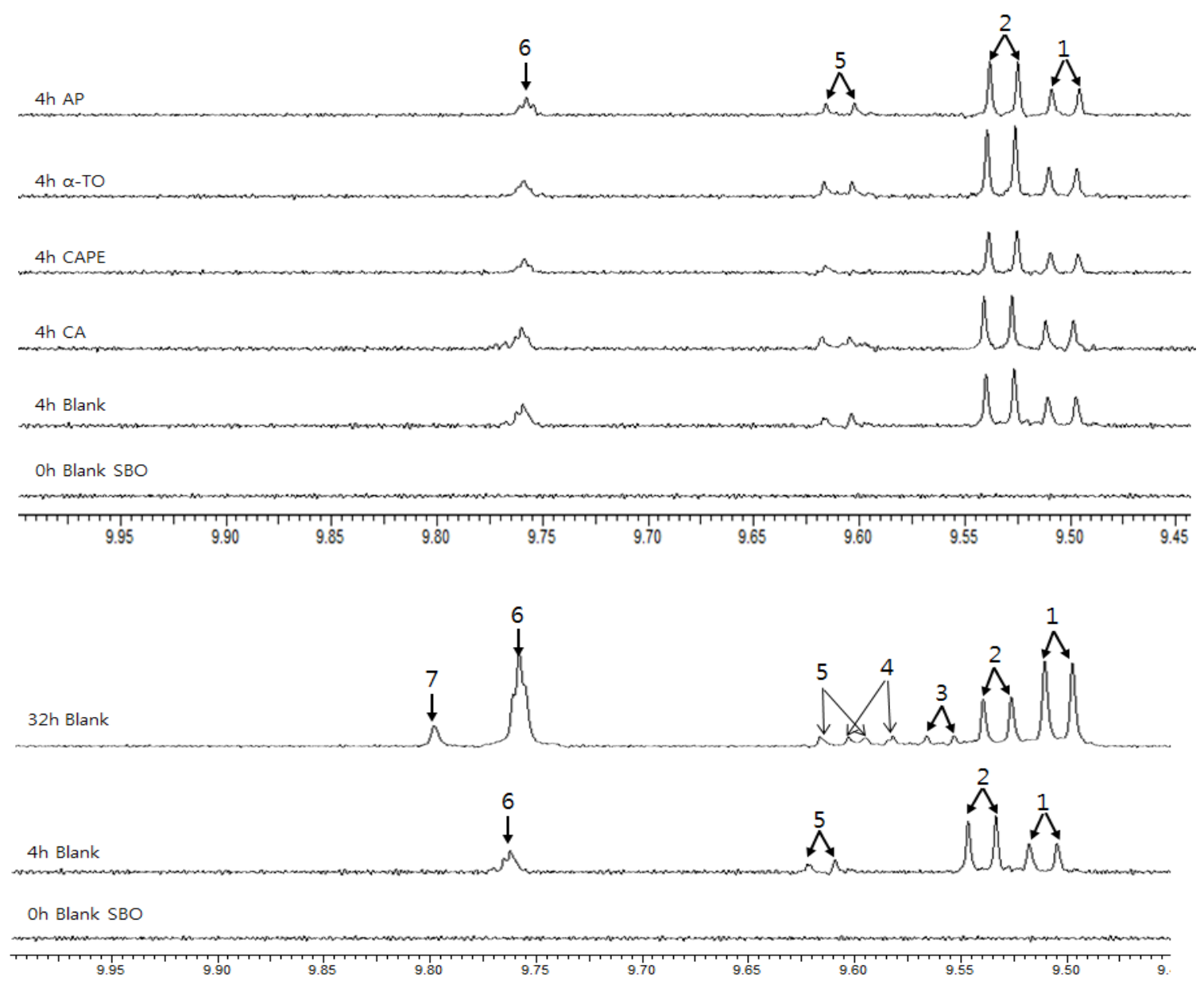

Fig. 1. Enlargement of the intensity between -0.0001 and 0.002 , and the region between 9.45 and 9.85 ppm of the ${ }^{1} \mathrm{H}-\mathrm{NMR}$ spectra of soybean oil (SBO) with different antioxidants, respectively, during thermal oxidation at $180^{\circ} \mathrm{C}$.

Signals: 1, (E)-2-alkenals; 2, (E,E)-2,4-alkadienals; 3, 4,5-epoxy-(E)-2-alkenals; 4, 4-hydroxy-(E)-2-alkenals; 5, (Z,E)-2,4-alkadienals; 6, n-alkanals; 7, 4-oxoalkanals. CA, caffeic acid; CAPE, caffeic acid phenethyl ester; a-TO, a-tocopherol; AP, ascorbyl palmitate. 
분석된 8-10 ppm 사이의 chemical shift에서 검출이 가능하 다고 하였다(8-10). 먼저 가열 산화하기 전인 $\mathrm{SBO}(0$ 시간 Blank SBO)에서는 9.45-9.8 ppm사이에서 유지 산화물로 예측되는 어떠한 peak도 나타나지 않았지만, 4 시간 가열한 $\mathrm{SBO}$ (4시간 Blank)에서는 (E)-2-alkenals와 (E,E)-2,4alkadienals를 포함한 aldehydes가 검출 되었고, 특히 32시간 가열 후에는 해당 peak들의 area가 커짐에 따라 산화물의 발생이 증가하였음을 알 수 있었다. (E,E)-2,4-alkadienals는 4시간 경과 후에 다른 aldehydes류보다 빠르게 형성되었다 가 32 시간로 가열이 지속됨에 따라 감소하는 경향을 보였 고, (E)-2-alkenals과 n-alkanals는 뚜렷하게 계속해서 생성되 는 양이 증가하는 것을 볼 수 있었다. 한편, 4,5-epoxy(E)-2-alkenals, 4-hydroxy-(E)-2-alkenals 그리고 4-oxoalkanals 는 4시간 보다는 32시간으로 가열시켰을 때 보다 많이 발생 되는 경향을 보였다(Fig. 1). 이와 같은 aldehydes류의 발생 은 $\mathrm{CAPE}$ 를 항산화물질로 사용하였을 때 가장 적었다. 가열 시간을 4시간하였을 때 $200 \mathrm{ppm}$ 의 $\mathrm{CAPE}$ 를 첨가한 $\mathrm{SBO}(4$ 시간 $\mathrm{CAPE})$ 는 어떠한 항산화물질을 첨가하지 않은 $\mathrm{SBO}(4$ 시간 Blank)뿐만 아니라 $200 \mathrm{ppm}$ 의 $\mathrm{AP}(4$ 시간 $\mathrm{AP}), \mathrm{CA}(4$ 시 간 $\mathrm{CA}$ ), 그리고 $\mathrm{a}-\mathrm{TO}(4$ 시간 $\mathrm{a}-\mathrm{TO})$ 을 첨가한 $\mathrm{SBO}$ 보다도 aldehydes peak의 area가 상대적으로 적었다. 이는 $\mathrm{CAPE}$ 의 첨가가 유지의 가열산화를 일정 부분 억제할 수 있다는 것을 의미한다고 할 수 있다.

\section{가열 중 색변화}

산화가 진행되는 유지에서 가장 눈에 띄게 변하는 현상 중 하나는 유지의 색이다. 일반적으로 가열 산화되는 시간 이 길어질수록 유지의 색은 초기 연한 노란색에서 점차 검붉은 색으로 어두워진다. 이는 유지의 산화 반응, 중합 반응 및 기타 화학 반응 등 복합적인 결과이다(13). 본 실험 에서는 산화 반응이 진행됨에 따라 유지의 색 변화를 육안 관측(Fig. 2) 및 Hunter parameters $\mathrm{L}^{*}, \mathrm{a}^{*}, \mathrm{~b}^{*}$ 그리고 $\Delta \mathrm{E}$ 로 나타내었다(Fig. 3-6). 육안으로 보았을 때 가열시간을 4시 간에서 32 시간으로 늘려감에 따라 가열된 $\mathrm{SBO}$ 의 색은 뚜 렷하게 진한 황색으로 변해가는 것을 관찰 할 수는 있었으 나 첨가된 항산화 물질에 따른 색의 차이를 비교하기에는

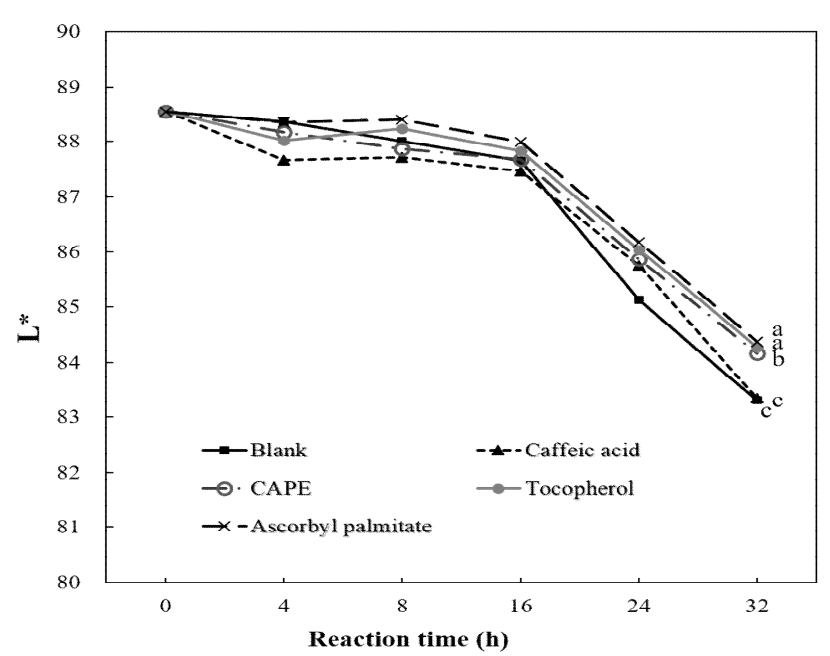

Fig. 3. The degree of brightness $\left(L^{*}\right)$ in soybean oil (SBO) with different antioxidants $(200 \mathrm{ppm})$ during thermal oxidation at $180^{\circ} \mathrm{C}$. Different letters $(a-c)$ means significant difference $(p<0.05)$ by Duncan's multiple range test.

어려움이 있었다. 일반적으로 유지의 색상은 Lovibond법을 이용하지만 본 연구에서는 색차계를 이용하여 $\mathrm{L}^{*}, \mathrm{a}^{*}, \mathrm{~b}^{*}$, $\Delta \mathrm{E}$ 의 차이를 나타내었다. $\mathrm{L}^{*}$ 은 명도를 나타내는 지표인데 가열 산화하기 전인 $\mathrm{SBO}(\mathrm{Blank})$ 는 88.5 의 값을 보였으나, 32 시간 가열 후에는 83.3 으로 약 $6 \%$ 감소하였다. 한편, 어떠 한 항산화제 $(\mathrm{CAPE}$ 및 $\mathrm{CA}, \mathrm{a}-\mathrm{TO}, \mathrm{AP})$ 를 첨가하였더라도 24 시간 동안의 $\mathrm{L}^{\star}$ 값 차이는 서로 간에는 크지 않았으나, 항산화제를 첨가하지 않은 Blank보다는 높은 $\mathrm{L}^{\star}$ 값을 보였 다. 반면에 32 시간 가열 후에서는 $\mathrm{CA}$ 를 첨가한 $\mathrm{SBO}$ 의 $\mathrm{L}^{*}$ 값이 Blank의 값과 유사하게 낮아지면서 CAPE, $\mathrm{a}-\mathrm{TO}$, 그리 고 $\mathrm{AP}$ 를 첨가한 $\mathrm{SBO}$ 의 $\mathrm{L}^{\star}$ 값과 유의적으로 차이를 보였다 $(\mathrm{p}<0.05)$ (Fig. 3). 그러나 $\mathrm{CA}$ 이외의 항산화제들(CAPE, a -TO, AP)은 Blank보다 높은 $\mathrm{L}^{*}$ 값을 보였기 때문에 오랜 가열 산화에 의하여 유지의 색상이 어두워지는 현상을 특정 항산화 물질이 어느 정도 억제 할 수 있을 것으로 사료된다. $\mathrm{a}$ *값은 낮을수록 초록색을, 그리고 높을수록 붉은색을 나 타내게 되는데 Blank의 경우 가열 산화하기 전에 -3.23 를 보였고, 이는 24시간 가열할 때 -10.12로 낮아지다가 이후

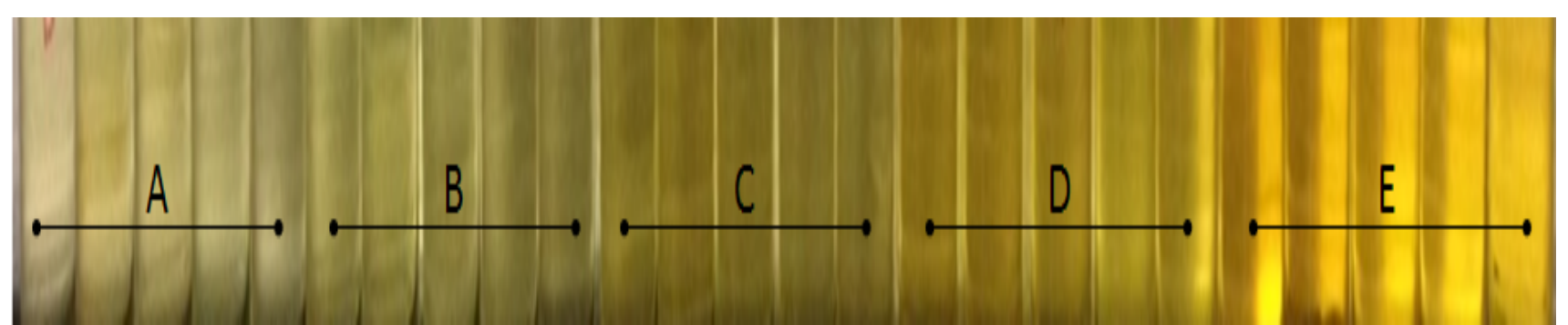

Fig. 2. Visual observation of color in soybean oil (SBO) with different antioxidants $(200 \mathrm{ppm})$ during thermal oxidation at $180^{\circ} \mathrm{C}$.

A-E represents the color change during oxidation at different reaction times.

A, oxidation reaction for $4 \mathrm{~h} ; \mathrm{B}, 8 \mathrm{~h} ; \mathrm{C}, 16 \mathrm{~h} ; \mathrm{D}, 24 \mathrm{~h} ; \mathrm{E}, 32 \mathrm{~h}$.

Sequence of treatments (antioxidants) from the left to the right: blank, caffeic acid, caffeic acid phenethyl ester, a-tocopherol, and ascorbyl palmitate. 
다시 증가하는 경향을 나타내었다(Fig. 4). 항산화제를 첨가 한 모든 $\mathrm{SBO}$ 에서도 Blank와 유사한 경향, 즉 가열 시간이 길어질수록 $\mathrm{a}^{\star}$ 값이 감소되다가 24 시간 이후 증가하는 경향 을 보였다. 32 시간 가열 후 사용된 항산화제들 중에서 $\mathrm{CA}$ 및 CAPE는 각각 -8.7, -8.9의 값을 보이면서 Blank보다 유의

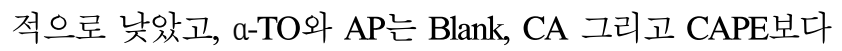
도 낮은 $\mathrm{a}^{\star}$ 값을 나타났다(p<0.05)(Fig. 4). $\mathrm{b}^{*}$ 값은 높을수록 노란색을 나타내게 되는데 가열시간이 길어질수록 모든 시료에서 점차 증가하였다(Fig. 5). 가열 산화하기 전인 $\mathrm{SBO}$ (Blank)의 경우 13 의 값에서 32 시간 가열 후에서는 74 까지 크게 증가하였다. 이는 육안으로 관찰하였을 때 모든 시료에서 뚜렷하게 황색으로 변한 것과 같은 결과로 볼 수 있다. 32 시간 가열 후 항산화제가 첨가된 $\mathrm{SBO}$ 에서 $\mathrm{b}^{\star}$ 값 은 69.9(AP), $a-\mathrm{TO}(71.8), \mathrm{CA}(72.04)$ 와 $\mathrm{CAPE}(72.50)$ 으로

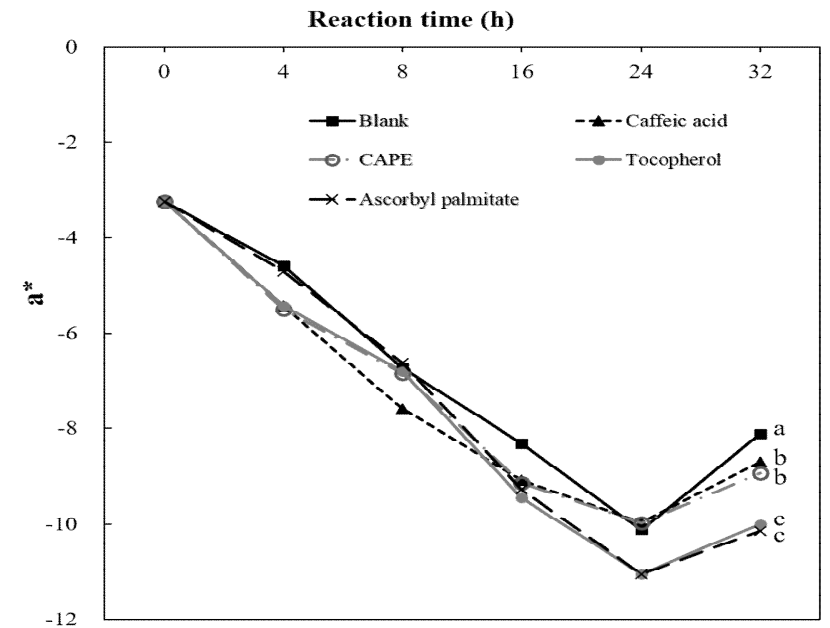

Fig. 4. The degree of redness $\left(a^{*}\right)$ in soybean oil (SBO) with different antioxidants $(200 \mathrm{ppm})$ during thermal oxidation at $180^{\circ} \mathrm{C}$. Different letters $(a-c)$ means significant difference $(p<0.05)$ by Duncan's multiple range test.

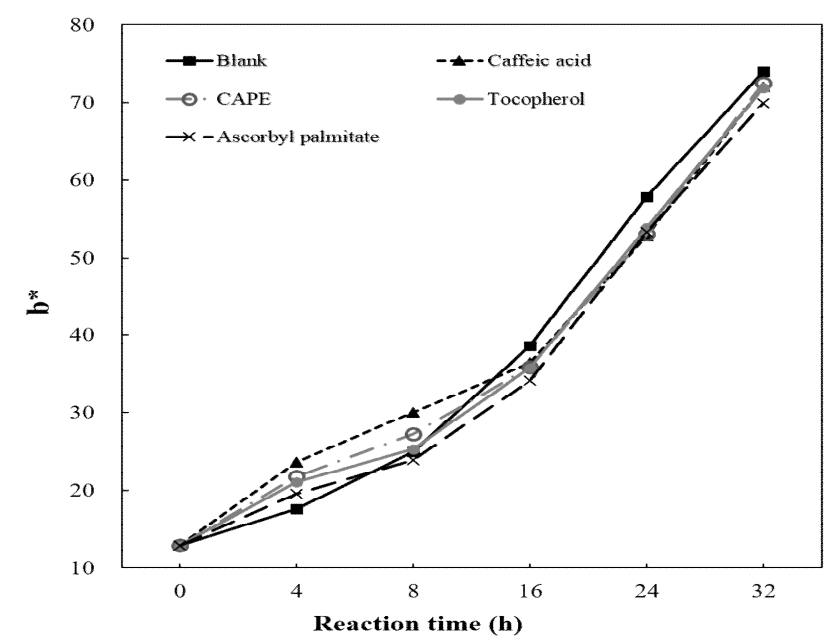

Fig. 5. The degree of yellowness $\left(b^{\star}\right)$ in soybean oil (SBO) with different antioxidant $(200 \mathrm{ppm})$ during the thermal oxidation at $180^{\circ} \mathrm{C}$.
서로 유사하게 측정되어 유의적 차이는 없었다( $\mathrm{p}>0.05)$. 한 편, 32 시간 가열 후 전체적인 색 변화를 나타내는 $\Delta \mathrm{E}$ (total color difference)의 순서는 Blank $>\mathrm{CA}=\mathrm{CAPE}=\mathrm{a}$-TO $>\mathrm{AP}$ 이었으나 서로간의 유의적 차이는 없었다( $\mathrm{p}>0.05)$ (Fig. 6). 가열 산화 유지에서 색의 변화는 원재료에 함유된 지용성 색소의 변화에 의한 영향과 중합체 생성물, 그리고 carbonyl 2차 산화물들이 주요 원인으로 알려져 있다 $(2,14,15)$. 또한, 식품을 유지에 튀겼을 경우에는 maillard reaction도 고려해 볼 수 있다. 유지 산화로부터 야기되는 carbonyl기와 식품으로부터 유리되는 amino기 간의 반응으 로 melanoidin과 같은 갈색물질을 생성하기 때문이다. Totani 등(16)은 가열 유지의 색 변화가 유지 자체의 가열적 열화가 주된 원인이며, 그 외에도 가열 산화된 기름이나 지방산 그리고 튀김 식품에서 나온 아미노산으로 형성된 amino-carbonyl 화합물이 기여한다고 설명하고 있다. 그러 나 본 실험에서는 식품의 첨가 없이 유지만 가열했기 때문 에 maillard 반응으로 야기되는 색변화가 크게 기여하지 않았을 것으로 추정된다. 한편, $\mathrm{Chu}$ 와 $\mathrm{Luo(17)}$ 는 유지의 색상 측정은 유지 성분과 튀기는 식품 성분 요소의 간섭 가능성으로 인해 유지 품질을 모니터링 하는데 적절하지 않다고 제시하였다.

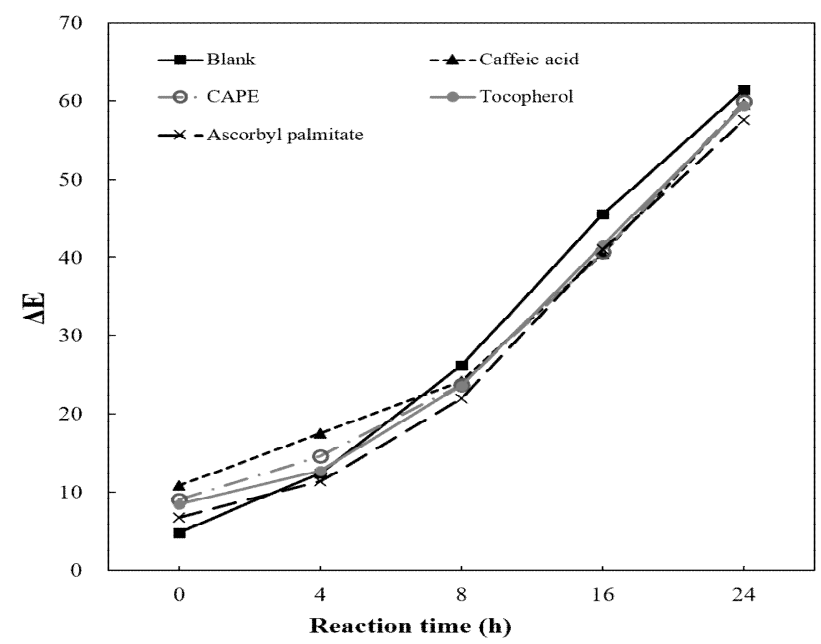

Fig. 6. The degree of the total color difference $(\Delta \mathrm{E})$ in soybean oil (SBO) with different antioxidants $(200 \mathrm{ppm})$ during thermal oxidation at $180^{\circ} \mathrm{C}$.

\section{Tocopherol의 감소율}

토코페롤 및 토코트리엔올은 자연적으로 발생하는 식물 성 기름에서 중요한 생체 활성 성분으로서 효율적인 alkoxyl 및 peroxide radicals 제거할 수 있는 주요 친유성 산화 방지제뿐만 아니라 활성 산소 및 활성 질소 등으로 야기되는 산화 스트레스로부터 인간을 보호하는 역할을 한다(18). Deep frying 조건에서의 유지는 가열 산화, 가수 분해와 같은 반응이 일어남에 따라 유지의 품질 악화뿐만 
아니라 토코페롤의 손실을 야기하며, 이는 유지의 안정성 감소로 이어져 튀겨진 식품의 유통 기한과 안정성에 대해 영향을 미칠 수 있다(19). 따라서 본 연구에서는 $\mathrm{SBO}$ 의 가열 산화 조건에서 첨가된 항산화제(CA, CAPE, $\mathrm{a}-\mathrm{TO}$ 및 $\mathrm{AP}$ )에 의한 토코페롤 손실 억제 정도를 평가하였다(Table 1). 실험에 사용된 $\mathrm{SBO}$ 은 $\mathrm{\gamma}>\mathrm{a}>\delta$ 순으로 각각 191,114 , 및 $14 \mathrm{ppm}$, 총 $319 \mathrm{ppm}$ 의 토코페롤을 함유하였다. 이는 여러 콩 품종의 토코페롤 isomer 함량 보고에서 $\mathrm{x}$-토코페롤

Table 1. Retention (\%) of tocopherol isomers in soybean oil (SBO) with different antioxidants $(200 \mathrm{ppm})$ during thermal oxidation at $180^{\circ} \mathrm{C}$

\begin{tabular}{|c|c|c|c|c|}
\hline \multirow{2}{*}{ Sample } & \multirow{2}{*}{ Heating time (h) } & \multicolumn{3}{|c|}{ Retention of tocopherol isomer $(\%)^{1)}$} \\
\hline & & $\mathrm{a}-\mathrm{TO}$ & $\mathrm{y}-\mathrm{TO}$ & $\delta$-TO \\
\hline Initial & 0 & 100 & 100 & 100 \\
\hline \multirow{5}{*}{ Blank } & 4 & 31.7 & 47.0 & 89.8 \\
\hline & 8 & 10.8 & 18.4 & 69.9 \\
\hline & 16 & 5.8 & 7.5 & 48.9 \\
\hline & 24 & - & 6.1 & 39.7 \\
\hline & 32 & - & 5.1 & - \\
\hline \multirow{5}{*}{$\mathrm{CA}$} & 4 & 41.0 & 32.2 & 83.0 \\
\hline & 8 & 17.7 & 18.5 & 60.7 \\
\hline & 16 & 6.3 & 8.0 & 52.0 \\
\hline & 24 & 2.5 & 5.4 & 29.2 \\
\hline & 32 & - & 5.1 & - \\
\hline \multirow{5}{*}{ CAPE } & 4 & 60.4 & 76.9 & 95.0 \\
\hline & 8 & 20.4 & 29.7 & 88.0 \\
\hline & 16 & 6.9 & 8.6 & 54.8 \\
\hline & 24 & 5.4 & 5.5 & 35.9 \\
\hline & 32 & 5.2 & 4.9 & - \\
\hline \multirow{5}{*}{$\mathrm{a}-\mathrm{TO}$} & 4 & $43.9^{2)}(121.2)$ & 30.8 & 82.1 \\
\hline & 8 & $21.5(59.1)$ & 21.1 & 75.1 \\
\hline & 16 & $4.2(11.4)$ & 10.7 & 59.1 \\
\hline & 24 & $3.0(8.2)$ & 6.1 & 27.7 \\
\hline & 32 & $2.8(7.7)$ & 3.3 & - \\
\hline \multirow{5}{*}{$\mathrm{AP}$} & 4 & 52.8 & 61.8 & 92.0 \\
\hline & 8 & 19.5 & 29.5 & 83.5 \\
\hline & 16 & 2.4 & 8.9 & 53.4 \\
\hline & 24 & - & 6.1 & 39.4 \\
\hline & 32 & - & 4.5 & - \\
\hline
\end{tabular}

CA, caffeic acid; CAPE, caffeic acid phenethyl ester; a-TO, a-tocopherol; AP, ascorbyl palmitate.

${ }^{1)}$ Tocopherol retention $(\%)=[($ Initial SBO tocopherol content-tocopherol content of each heating time) / initial SBO tocopherol content] $\times 100$.

${ }^{2)} \mathrm{a}-\mathrm{TO}(\%)=[($ Initial SBO tocopherol content $+200 \mathrm{ppm}$ a-tocopherol)-(tocopherol content of each heating time) / initial SBO tocopherol content] $\times 100$.

Initially, SBO contains $114 \mathrm{ppm}$ of a-tocopherol, $191 \mathrm{ppm}$ of $\mathrm{y}$-tocopherol, and $14 \mathrm{ppm}$ of $\delta$-tocopherol.
의 함량이 가장 많았다는 결과와 같다(20). 유지의 가열 산화가 진행됨에 따라 토코페롤은 모든 시료에서 급격하게 손실되었는데, $\delta$ - 보다는 a- 및 $\mathrm{\gamma}$-토코페롤에서 함량의 감소 변화가 뚜렷하였다. 특히, 4시간 가열 후 항산화제를 첨가 한 모든 $\mathrm{SBO}$ 의 a-토코페롤 함량 변화는 Blank(항산화제 미첨가 $\mathrm{SBO}$ )보다 적었는데, $\mathrm{a}$-토코페롤의 잔존율(retention) 은 $\mathrm{CAPE}(60.4 \%)>\mathrm{AP}(52.8 \%)>a-\mathrm{TO}(43.9 \%)>\mathrm{CA}(41.0 \%)$ $>\operatorname{Blank}(31.7 \%)$ 순이었고, 이와 같이 항산화제를 첨가하였 을 때 Blank보다 높은 잔존율(retention)이 나타나는 결과는 8시간 가열 후에서도 보였다(Table 1). 특히 a-TO는 200 $\mathrm{ppm}$ 의 a-토코페롤을 첨가하였기 때문에 다른 시료들보다 도 많은 총 $314 \mathrm{ppm}$ 의 $\mathrm{a}$-토코페롤을 함유하고 있었으나, 4시간 가열 후의 잔존율은 $\mathrm{CAPE}$ 와 $\mathrm{AP}$ 보다도 낮았다. 32 시 간 가열 후에서는 $a-\mathrm{TO}$ 와 $\mathrm{CAPE}$ 를 제외한 나머지 항산화제 첨가 시료들에서 $a$-토코페롤은 검출되지 않았고, $\mathrm{CAPE}$ (5.2\%)에서 $\mathrm{a}-\mathrm{TO}(2.8 \%)$ 보다 잔존율이 높았다. Gordon과 Kourimská(21)에 따르면 튀김 온도에서 a-토코페롤이 가장 빨리 손실된다고 하였으며, 산화에 더 활동적인 항산화제 의 존재는 토코페롤의 손실을 억제시킬 수 있는데, 로즈메 리 추출물이나 ascorbyl palmitate의 사용이 토코페롤의 손 실 속도를 줄일 수 있다고 하였다. $\gamma$-토코페롤은 a-토코페롤 과 다소 다른 경향의 잔존율을 보였다. 4시간 가열 후의 $\mathrm{x}$-토코페롤 잔존율은 $\mathrm{CAPE}(76.9 \%)>\mathrm{AP}(61.8 \%)>\mathrm{Blank}$ $(47.0 \%)>\mathrm{CA}(32.2 \%)>\mathrm{a}-\mathrm{TO}(30.8 \%)$ 순이었고, 이유가 명확하지는 않으나 $\mathrm{CA}$ 와 a-TO가 Blank보다도 낮은 $\mathrm{\gamma}$-토코 페롤 잔존율을 나타내었다. 그러나 8시간 가열 후에서는 $\mathrm{CAPE}(29.7 \%) \geq \mathrm{AP}(29.5 \%)>\mathrm{a}-\mathrm{TO}(21.1 \%)>\mathrm{CA}(18.5 \%)$ $\geq \operatorname{Blank}(18.4 \%)$ 의 순서로 $\mathrm{\gamma}$-토코페롤 잔존율을 보였고, 이후 모든 시료에서 점차적인 감소를 보이면서 32시간 가 열 후에는 3.3-5.1\%의 $\gamma$-토코페롤 잔존율이 나타났다(Table 1). 한편, 실험에 사용된 항산화제들 중에서 가장 polar한 성질을 가지고 있는 $\mathrm{CA}$ 는 $\gamma$-토코페롤의 손실을 억제하는 데 뚜렷한 효과를 보이지 못했다. 이러한 이유는 CA가 항산 화제로서의 역할을 수행할 때, CA가 토코페롤보다 산화되 는 속도가 느리기 때문이라 생각된다. Reblova 등(22)은 8가지의 페놀산(gallic, gentisic, protocatechuic, syringic, vanillic, ferulic, caffeic, 그리고 sinapic acid) 중에서 다른 페놀산보다 free radical의 소거능이 가장 큰 gallic acid를 제외한 나머지 물질에서는 산화 과정중의 $a-$ 토코페롤 손실 에 대해서 효과를 볼 수 없었다고 보고하였다. 결론적으로 $200 \mathrm{ppm}$ 의 $\mathrm{CAPE}$ 와 $\mathrm{AP}$ 는 초기 가열시간인 4시간과 8시간 에서는 토코페롤 이성체들의 손실을 억제할 수 있었으나 16 시간이후에서는 큰 영향을 미치지 않는 것으로 생각되 며, $200 \mathrm{ppm}$ a-토코페롤의 첨가는 가열 산화시에 $a$-토코페 롤 잔존에도 효과가 크지 않았다고 할 수 있다. 그럼에도 불구하고 CAPE는 실험에 사용된 다른 어떤 항산화제들보 다 초기 가열시간동안 토코페롤 이성체들의 손실을 억제하 는데 가장 큰 효과가 있었다. 


\section{요 약}

${ }^{1} \mathrm{H}-\mathrm{NMR}$ 을 이용하여 유지의 2 차 산화물류의 발생 변화 량을 살펴보았을 때, $200 \mathrm{ppm}$ 의 $\mathrm{CAPE}$ 첨가는 $\mathrm{AP}, \mathrm{CA}$, 그리고 $a$-토코페롤을 첨가하였을 때 보다 aldehydes peak의 area가 뚜렷하게 적었고, 이는 CAPE의 첨가가 유지의 가열 산화를 일정 부분 억제할 수 있다는 것을 의미한다고 할 수 있다. CAPE, a-TO, 그리고 AP 첨가구에서는 blank보다 32 시간 가열된 유지에서 유의적으로 높은 $\mathrm{L}^{*}$ 값을 보였으 나, 전체적인 색 변화를 나타내는 $\Delta \mathrm{E}$ (total color difference) 는 서로 간의 값 차이가 크지 않았다. 가열 산화 시에 손실되 는 토코페롤 이성체들의 잔존율을 살펴본 결과, $\delta$ - 보다는 $a-$ 및 $\mathrm{z}$-토코페롤에서 함량의 감소 변화가 컸으며, 실험에 사용된 항산화제들 중에서 가장 극성의 성질을 가지고 있는 $\mathrm{CA}$ 는 $\mathrm{CAPE}$ 와 $\mathrm{AP}$ 보다 $\mathrm{\gamma}$-토코페롤의 손실을 억제하는데 뚜렷한 효과를 보이지 못했다. 그러나 CAPE는 실험에 사용 된 다른 어떤 항산화제들보다 초기 가열시간동안 토코페롤 이성체들의 손실을 억제하는데 가장 큰 효과가 있었다.

\section{References}

1. Belitz HD, Grosch W (1999) Food Chemistry. $2^{\text {nd }}$ ed, Springer, Berlin, German, p 152-158

2. Choe E, Min DB (2007) Chemistry of deep-fat frying oils. J Food Sci, 72, 77-86

3. Aladedunye FA, Przybylski R (2009) Degradation and nutritional quality changes of oil during frying. $\mathrm{J}$ Am Oil Chem Soc, 86, 149-156

4. Warner K (1997) Chemistry of frying fats. In: Food Lipids, Akoh CC, Min DB (Editor), Marcel Dekker Inc., NY, USA, p 167-180

5. Dobarganes C, Marquez-Ruiz G (2003) Oxidized fats in foods. Curr Opin Clin Nutr Metab Care, 6, 157-163

6. Onal B, Ergin G (2002) Antioxidative effects of a -tocopherol and ascorbyl palmitate on thermal oxidation of canola oil. Nahrung, 6, 420-426

7. Widjaja A, Yeh TH, Ju YH (2008) Enzymatic synthesis of caffeic acid phenethyl ester. J Chin Inst Chem Eng, 39, 413-418

8. Jia CH, Shin JA, Lee KT (2015) Effects of caffeic acid phenethyl ester and 4-vinylcatechol on the stabilities of oil-in-water emulsions of stripped soybean oil, J Agric Food Chem, 63, 10280-10286

9. Guillen MD, Ruiz A (2005) Monitoring the oxidation of unsaturated oils and formation of oxygenated aldehydes by proton NMR. Eur J Lipid Sci Technol, 107,
36-47

10. Shin JA, Jeong SH, Jia CH, Hong ST, Lee KT (2019) Comparison of antioxidant capacity of 4-vinylguaiacol with catechin and ferulic acid in oil-in-water emulsion. Food Sci Biotechnol, 28, 35-41

11. Ministry of Food and Drug Safety (2017) NLS Standard Operating Procedure Analytical Methods. Korea Food and Drug Administration, Osong, Korea. p 131-137

12. SAS (2002) SAS User's Guide: Statistics, 9.2 version, SAS Institute Statistical Analysis System, Cary, NC, USA

13. Tan YA, Ong SH, Berger KG, Oon HH, Poh BL (1985) A study of the cause of rapid color development of heated refined palm oil. J Am Oil Chem Soc, 62, 999-1006

14. Maskan M (2003) Change in colour and rheological behaviour of sunflower seed oil during frying and after adsorbent treatment of used oil. Eur Food Res Technol, $218,20-25$

15. Subramanian R, Nandini KE, Sheila PM, Gopalakrishna AG, Raghavarao KSMS, Nakajima M, Kimura T, Maekawa T (2000) Membrane processing of used frying oils. J Am Oil Chem Soc, 77, 323-328

16. Totani N, Kuzume T, Yamaguchi A, Takada M, Moriya M (2006) Amino acids brown oil during frying. J Oleo Sci, 55, 441-447

17. Chu YH, Luo S (1994) Effects of sugar, salt and water on soybean oil quality during deep-frying. J Am Oil Chem Soc, 71, 897-900

18. Gliszczynska-Swiglo A, Sikorska E, Khmelinskii I, Sikorski M (2007) Tocopherol content in edible plant oils. Pol J Food Nutr Sci, 57, 157-161

19. Yuki E, Ishikawa Y (1976) Tocopherol contents of nine vegetable frying oils, and their changes under simulated deep-fat frying conditions. J Am Oil Chem Soc, 53, 673-676

20. Rani A, Kumar V, Verma SK, Shakya AK, Chauhan GS (2007) Tocopherol content and profile of soybean: Genotypic variability and Correlation studies. J Am Oil Chem Soc, 84, 377-383

21. Gordon MH, Kourimska L (1995) Effect of antioxidants on losses of tocopherols during deep-fat frying. Food Chem, 52, 175-177

22. Reblova Z, Fisnar J, Tichovska D, Dolezal M, Joudalova K (2012) Effect of temperature and oil composition on the ability of phenolic acids to protect naturally present a-tocopherol during the heating of plant oils. Czech $\mathbf{J}$ Food Sci, 30, 351-357 